\title{
Odontología Forense I: Las Huellas de Mordedura
}

\author{
Forensic Dentistry I: Bite Marks
}

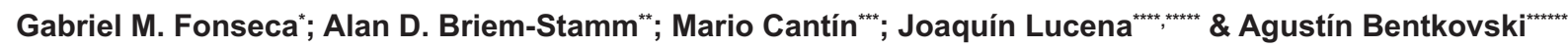

FONSECA, G. M.; BRIEM-STAMM, A. D.; CANTÍN, M.; LUCENA, J. \& BENTKOVSKI, A. Odontología Forense I: Las huellas de mordedura. Int. J. Odontostomat., 7(1):149-157, 2013.

RESUMEN: Entre las pericias de identificación odontológica forense, los análisis de huellas de mordedura han representado un tópico actual, relevante y controvertido pues la unicidad de la dentición, la confiabilidad de la piel como soporte y sus técnicas de análisis, han visto un fuerte cuestionamiento a partir de una relevante casuística de condenas injustas. Mientras la literatura especializada y más actual ofrece una permanente revisión sobre protocolos y normas para la cualificación de pericias y peritos, la literatura de habla hispana no sostiene un ritmo similar, con una escasa o nula actualización de contenidos adecuados en procedimientos, investigación o reportes de casos. Dado que estos análisis ha sufrido cambios absolutos de base, y que una conveniente actualización al habla hispana permitiría la adaptación, modificación o reemplazo de sus postulados axiológicos, se presenta una revisión cronológica sobre casos y tópicos de inferencia en el análisis de huellas de mordeduras como evidencia jurídica, y se proponen y discuten nuevos postulados epistemológicos para el abordaje forense de este tipo de evidencias.

PALABRAS CLAVE: odontología forense, huellas de mordedura, análisis de huellas de mordedura, condenas injustas.

\section{INTRODUCCIÓN}

La Odontología Forense define la relación del odontólogo con la Justicia, correspondencia que se ve expresada en diferentes pericías, todas necesitadas de una sólida formación del profesional. Entre éstas, las identificativas han significado un gran aporte a las ciencias forenses, donde los análisis de huellas de mordedura representan un tema relevante en la moderna odontología forense. Sin embargo, cuando estas huellas son la única evidencia que relaciona al agresor con la víctima, la habilidad del perito y la validez de sus técnicas de análisis han originado importante controversia (Pretty \& Sweet, 2010). Los axiomas defendidos hasta ahora de una supuesta unicidad de la dentición y la posibilidad de que ésta sea transferida a la piel son notablemente cuestionadas en la actualidad a partir de una relevante casuística internacional de condenas injustas (Pretty \& Bowers, 2011). Como respuesta, legislaciones y sociedades científicas han desplegado protocolos y normas para validar técnicas y peritos (American Board of Forensic Odontology, 2013). Se ha informado que la mayor parte de estas pericias han incurrido en errores como identificar mordeduras en heridas que no lo eran o en dar certeza absoluta a dictámenes que distaban mucho de poseerla (Pretty \& Bowers).

Mientras la literatura científica especializada y más actual ofrece una permanente revisión de esta pericia (Page et al., 2013), se ha mencionado que la literatura de habla hispana no sostiene un ritmo similar, con una escasa o nula actualización de contenidos adecuados en procedimientos, investigación o

\footnotetext{
Profesor Titular, Cátedra de Anatomía Patológica B, Facultad de Odontología, Universidad Nacional de Córdoba, Córdoba, Argentina. “ Especialista en Odontología Legal y Forense, Docente Especialidad de Odontología Legal y Forense, Facultad de Odontología, Universidad Nacional del Nordeste, Corrientes, Argentina.

*** Programa de Doctorado en Ciencias Morfológicas. Profesor Asistente, Departamento Odontología Integral Adultos, Facultad de Odontología, Universidad de La Frontera, Temuco, Chile.

Profesor, Departamento de Medicina Forense, Universidad de Cádiz, Cádiz, España.

...*** Servicio de Patología Forense, Instituto de Medicina Legal, Sevilla, España.

*artu* Cátedra de Anatomía Patológica B, Facultad de Odontología, Universidad Nacional de Córdoba, Córdoba, Argentina.
} 
reportes de casos (De los Ríos \& Barriga, 2011). Dado que esta experticia ha sufrido cambios absolutos de base, y que una conveniente actualización permitiría la adaptación, modificación o reemplazo de sus postulados axiológicos (Pretty \& Sweet, 2010), se presenta una revisión cronológica sobre casos y temas de inferencia en el análisis de huellas de mordeduras como evidencia jurídica. Finalmente, se proponen y discuten nuevos postulados epistemológicos para el abordaje forense de este tipo de evidencias.

\section{LOS ANTECEDENTES}

1870. Ansil L. Robinson (EE.UU.) fue acusado de asesinato. Sobre el principio de unicidad y con modelos dentales, tres odontólogos identificaron a Robinson como único culpable de haber mordido a la víctima. Sin embargo, el alegato de que los modelos no replicaban exactamente una boca fue aceptado por el jurado, y Robinson fue exonerado originando el primer documento judicial en los EE.UU. sobre la presentación de estas evidencias en juicio (Pierce et al., 1990).

1954. James A. Doyle (EE.UU.) fue condenado por robo, identificado por su mordedura en un trozo de queso. La defensa apeló el fallo argumentando que la prueba era auto-incriminatoria. Aunque la apelación fue denegada, el caso estableció antecedentes para la futura Quinta Enmienda Constitucional (Senn, 2011).

1969. Wayne Boden (Canadá) fue acusado de asesinar a varias mujeres en las que dejaba profundas mordeduras. Aun sin contar con literatura especializada, los peritos encontraron las coincidencias suficientes para condenar a cadena perpetua a Boden (Kennedy, 2011).

1970. La American Academy of Forensic Sciences (AAFS) reconoció a la odontología forense como especialidad y ese mismo año se creó la American Society of Forensic Odontology (ASFO). En 1972, Ia Canadian Society of Forensic Science (CSFS) desarrolló su propia sección de Odontología Forense (Senn).

1972. Milton Johnson (EE.UU.) fue condenado por el asalto y violación de una joven. Un odontólogo le identificó después de comparar sus modelos dentales con una fotografía de una huella de mordedura en la víctima. La defensa apeló la evidencia pero fue desestimada (Lipton et al., 2013).
1974. Walter Marx (EE.UU.) fue identificado por un equipo de odontólogos (Gerald Felando, Reidar Soagnnes y Gerarld Vale) en el cotejo entre los modelos dentales del sospechoso y las réplicas de la nariz mordida de la víctima. Aunque la defensa rechazó la técnica, la corte admitió su uso sentando un importante precedente jurídico. Este caso representa hoy el gold standard y la primera participación de odontólogos forenses trabajando en equipo (Pretty \& Sweet, 2006).

1976. Richard Milone (EE.UU.) fue condenado por el asesinato de una niña. El caso es aún hoy conocido como la "batalla de los peritos" con 11 odontólogos forenses involucrados: Lester Luntz, Harold Perry, Irvin Sopher, Steven Smith, Raymond Rawson y Larry Pierce (por la fiscalía), y Lowell Levine, Curtis Mertz, Paul Stimson, Duane Devore y Homer Campbell (por la defensa). Las permanentes apelaciones y la introducción de nueva evidencia apuntando a otro sospechoso solo complicaron un caso que finalmente no fue favorable a Milone. Podría decirse que representa la contracara del caso Marx y el mejor ejemplo de la falta de un criterio único en la valoración de estas evidencias (Senn \& Souviron, 2010).

Ese mismo año, el American Board of Forensic Odontology (ABFO) fue creado con el auspicio de la AAFS, la asistencia de la National Association of Medical Examiners (NAME) y un staff de prestigiosos fundadores: Edward Woolridge, Richard Souviron, C. Mertz (primer presidente), Arthur Goldman, G. Vale, Stanley Schwartz, L. Levine, Robert Dorion, P. Stimson, David Scott, Manuel Maslansky y George Ward (Senn).

\section{EL APOGEO}

1979. Theodore "Ted" Bundy (EE.UU.) fue arrestado después de asesinar a treinta y tres estudiantes. Una huella de mordedura, encontrada en una de las víctimas, posibilitó que la fiscalía convocara a los odontólogos R. Souviron, L. Levine y N. Sperber. Gracias a una perfecta presentación por parte de Souviron y las confirmaciones de Levine y Sperber, el jurado sentenció a muerte a Bundy. El fuerte impacto en la opinión pública y el manejo procesal de la evidencia bastaron para establecer la credibilidad y la utilidad identificatoria de la técnica. La resolución favorable se debió sin duda al excelente estado de las huellas, las características distintivas dentarias de Bundy y la conformación de un equipo pericial de odontólogos, todos elementos probados exitosamente ya en el caso Marx (Silver \& Souviron, 2009). En esos mismos días y en un lugar próximo, Roy Allen Stewart 
fue también sentenciado a muerte en otro caso de identificación por análisis de una mordedura en la cadera de una mujer violada y asesinada. Por la fiscalía actuó Souviron y por la defensa Levine (quien no pudo testificar pues se encontraba haciéndolo en el caso Bundy (Lipton et al.; Senn \& Souviron).

1984. El ABFO emitió las Guías para el Análisis de Huellas de Mordeduras, para brindar respaldo técnico y de procedimiento al odontólogo forense (American Board of Forensic Odontology). Posteriormente serían adoptadas la escalimetría -ABFO No. 2 para evitar distorsiones fotográficas, y las metodologías de cotejo digital, hoy procedimientos reconocidos en EE.UU., Europa, Asia y Oceanía (De los Ríos \& Barriga).

\section{LA CONTROVERSIA}

1989. Gary Dotson y David Vazquez fueron exonerados y liberados de prisión (después de años de encarcelamiento por evidencia forense) gracias a las nuevas tecnologías de ADN (Collins \& Jarvis, 2009).

1992. The Innocence Project (www. innocenceproject.org) fue fundado para la detección de condenas injustas, identificando mediante pruebas genéticas unas 300 a la fecha, entre ellas 18 condenas a muerte. Es extrema su posición respecto al análisis de las mordeduras humanas: "...comparar los dientes de un acusado con las huellas en el cuerpo de la víctima es, de lejos, subjetivo y propenso a error" (Pretty \& Bowers; Collins \& Jarvis).

1993. Estándares Daubert. En un fallo muy controvertido, la corte se expidió a favor de Merrell Dow Pharmaceuticals pues los demandantes no logran probar científicamente la relación entre el fármaco Bendectin y las malformaciones de Jason Daubert y Eric Schuller. Esto determinó cuáles serían a futuro los estándares judiciales federales para admitir evidencia científica: a) que la técnica haya sido probada en campo, b) que haya sido sometida a revisión por pares y publicada, c) que posea un índice de error conocido, d) que existan normas para su control y e) que haya sido aceptada por la comunidad científica (Beecher-Monas, 2009). Aún variando entre un estado y otro en los EE.UU., han logrado regular la admisibilidad tanto de peritos como de sus pericias y han sido claramente influyentes en países como Canadá, Inglaterra y Gales (lawcommission. justice.gov.uk).
1995. Anthony Otero (EE.UU.) fue acusado de asesinato por las pericias de un odontólogo forense quien testificó que era "la única persona en el mundo" que podría haber infligido las mordeduras presentes en la víctima. El informe de R. Souviron alegando la imposibilidad de análisis de esas huellas, y las posteriores pruebas de $A D N$, permitieron la exoneración de Otero después de cinco meses en prisión (BeecherMonas).

1997. Dale Morris Jr. (Pasco, Florida -EE.UU.) fue arrestado en 1997, gracias al informe de dos odontólogos forenses sobre una mordedura en el hombro de una niña violada, torturada y asesinada. El acusado pasó cuatro meses en prisión hasta que las pruebas de ADN realizadas por The Innocence Project confirmaron su inocencia (Beecher-Monas).

1998. Edmund Burke (EE.UU.) fue liberado después de 41 días de arresto por la violación y asesinato de una anciana. Si bien las pruebas de ADN le habían excluido, la fiscalía prefirió el informe de L. Levine donde identificaba con un "razonable grado de certeza científica" al acusado mediante el análisis de las huellas de mordedura presentes en los pechos de la víctima. Así mismo, nueva evidencia facilitó su liberación con lo que Burke demandó luego a policías y peritos, aunque fue desestimada (Fisher, 2008).

2000. James O'Donnell (EE.UU.) fue condenado en 1998 por intento de violación y agresiones. Aunque un testigo ocular no lo identificó positivamente y O'Donnell poseía coartada, la corte lo condenó basándose en la identificación visual de otro testigo y una supuesta mordedura en la mano de la víctima. Más tarde, las pruebas de ADN demostraron que O'Donnell no era el autor. Fue liberado en abril del año 2000 (Pretty \& Bowers; Pretty \& Sweet, 2010; Lipton et al.).

2001. Calvin Washington y Joe Sidney Williams (EE.UU.) fueron sentenciados a cadena perpetua en 1987 por violación y asesinato gracias al análisis de huella de mordedura realizado por un odontólogo forense. Después de 13 años, Washington resultó vindicado gracias a las pruebas de ADN que implicaron a otro hombre, que se suicidó tras admitir haber violado también a una anciana vecina de la víctima del homicidio (Pretty \& Bowers; Pretty \& Sweet, 2010).

2002. Ray Krone (EE.UU.) fue condenado y sentenciado a muerte en 1992 por violación y asesinato. Las huellas de mordeduras en la víctima fueron anali- 
zadas por un odontólogo local sin experiencia forense. Este identificó positivamente al acusado, básicamente por una malposición dentaria muy visible tanto en su boca como en la huella, informe que fue ratificado por otro odontólogo certificado por el ABFO. Krone fue condenado a muerte y tras la apelación se desarrolló un segundo juicio en 1996. Cuatro odontólogos forenses certificados, G. Vale, H. Campbell, N. Sperber y R. Souviron, excluyeron a Krone como el autor de la huella de mordedura (Senn \& Souviron), pero la Corte lo encontró culpable por segunda vez. Sin embargo, el juez cambió la pena a cadena perpetua pues a su entender existían "demasiadas preguntas sin respuesta en el caso" (Fisher). Más de 10 años después (parte de ese tiempo en el corredor de la muerte), Krone fue liberado gracias a pruebas de ADN que le excluyeron y demostraron que el autor era Kenneth Phillips, un violador ya condenado (Pretty \& Bowers; Lipton et al.).

2002. Raymond J. Carroll (Australia) protagonizó uno de los más importantes vacíos legales australianos. En 1973, un odontólogo identificó una huella de mordedura difusa en el muslo de una pequeña niña violada y asesinada. Doce años después, tres odontólogos examinaron a Carroll como sospechoso de aquella muerte y, aunque existían cambios lógicos en su dentadura, le identificaron como el autor de la mordedura. La corte encontró estas metodologías inconsistentes, lo que sumado a una coartada de Carroll, determinó su exoneración. En 2002, Carroll es acusado de perjurio (un testigo le ubicó en el momento y lugar del crimen); nuevos cotejos y técnicas le identificaron nuevamente como el autor. Sin embargo, la corte se declaró en conflicto ya que "nadie puede ser juzgado dos veces por la misma causa". Carroll fue exonerado (Clement \& Blackwell, 2010).

Michael Anthony Lewis (Australia) había sido condenado en 1986 por la violación de una joven y agresión a su novio. Aunque no existía otra evidencia vinculándole con los ataques, dos odontólogos forenses identificaron con un $100 \%$ de certeza a Lewis como el autor de la mordedura en el pecho del muchacho. Sin embargo en 1987, la corte decidió liberarlo tomando el caso Carroll como precedente (la evidencia era insuficiente para generar convicción). Clement \& Blackwell mencionan que al día siguiente de la violación; Lewis recibió múltiples golpes y lesiones en sus dientes por los que necesitó reposicionamientos, extracciones y rehabilitaciones por parte de un odontólogo. Esto supone una considerable disminución en la fiabilidad de la identificación realizada por los odontólogos forenses.
2005. Dan Young Jr. y Harold Hill (EE.UU.) fueron arrestados en 1992 por violación y asesinato, basados en el análisis de una huella de mordedura en la víctima. En 2005, nueva evidencia genética y el aporte del reconocido David Sweet (quien testificó la imposibilidad de peritar la herida por la cantidad de artefactos postmortem), permitieron la exoneración de ambos sentenciados (Pretty \& Bowers; Pretty \& Sweet, 2010, Lipton et al.).

2006. Willie Jackson (EE.UU.) fue exonerado y su hermano implicado en un caso de violación. En 1989, la víctima había reconocido a Jackson en rueda de testigos. Un odontólogo forense calificado le identificó a partir del análisis de las huellas de mordedura en la espalda de la víctima. Aunque su hermano confesó el crimen, no fue procesado y Jackson debió cumplir 17 años en prisión. Su liberación fue posible gracias a pruebas de ADN y una nueva pericia odontológica que demostró los sesgos del informe original y la coincidencia con la dentadura del hermano de Jackson (Pretty \& Bowers; Pretty \& Sweet, 2010; Lipton et al.).

2007. Roy Brown (EE.UU.) fue acusado y tomado en custodia en 1992 por asesinato. Aunque no existía conexión alguna con la víctima, la relación entre ambos fue establecida por una huella de mordedura analizada por un odontólogo sin experiencia forense quien incluso justificó las discrepancias entre huella y dentadura del acusado. El odontólogo de la defensa, H. Campbell, dejó claro que esto solo era explicable porque Brown no había mordido a la víctima. Así y todo, el jurado prefirió el testimonio del perito de la fiscalía encontrando culpable a Brown y sentenciándole a cadena perpetua (Pretty \& Bowers; Fisher). Quince años después, en 2007, las pruebas genéticas determinaron que otro individuo era el verdadero culpable del crimen lo que exoneró a Brown. Solo entonces pudo ser hospitalizado y sometido a trasplante por una enfermedad hepática desarrollada en prisión (Pretty \& Bowers; Fisher).

2008. Kennedy Brewer y Levon Brooks (EE.UU.), si bien casos diferentes en los inicios, compartieron mucho en su definición. Brewer fue condenado a muerte en 1992 por violación y asesinato, basado en gran parte en las huellas de mordeduras analizadas por el controvertido odontólogo forense M.W. Por la defensa, R. Sourivon declaró que las lesiones eran solo efecto de la acción animal. El jurado dio peso a la acusación con lo que Brewer fue condenado a inyección letal. Dos años antes, en 1990, el mismo 
M.W. testificaba que las huellas de mordedura en las muñecas de una niña violada y asesinada, habían sido producidas por Levon Brooks, quien también había sido condenado a muerte (Senn \& Souviron; Fisher).

En el año 2001, y a instancias de The Innocence Project, las pruebas genéticas excluyeron a Brewer pero la fiscalía desatendió esta nueva evidencia e intentó reprocesarle basándose solo en las huellas de mordedura. Por la defensa, lan Pretty, D. Sweet y David
Senn reafirmaron que las heridas no eran huellas de mordedura (un entomólogo testificó que habían sido causadas por cangrejos de río), por lo que compararlas con la dentición de Brewer era un sinsentido (Senn \& Souviron). Identificado e interrogado el verdadero culpable, confesó haber cometido los asesinatos endilgados a Brewer y Brooks, pero negando haber mordido a las víctimas. Después de su confesión, ambos inocentes fueron liberados en el año 2008 (Lipton et al.).

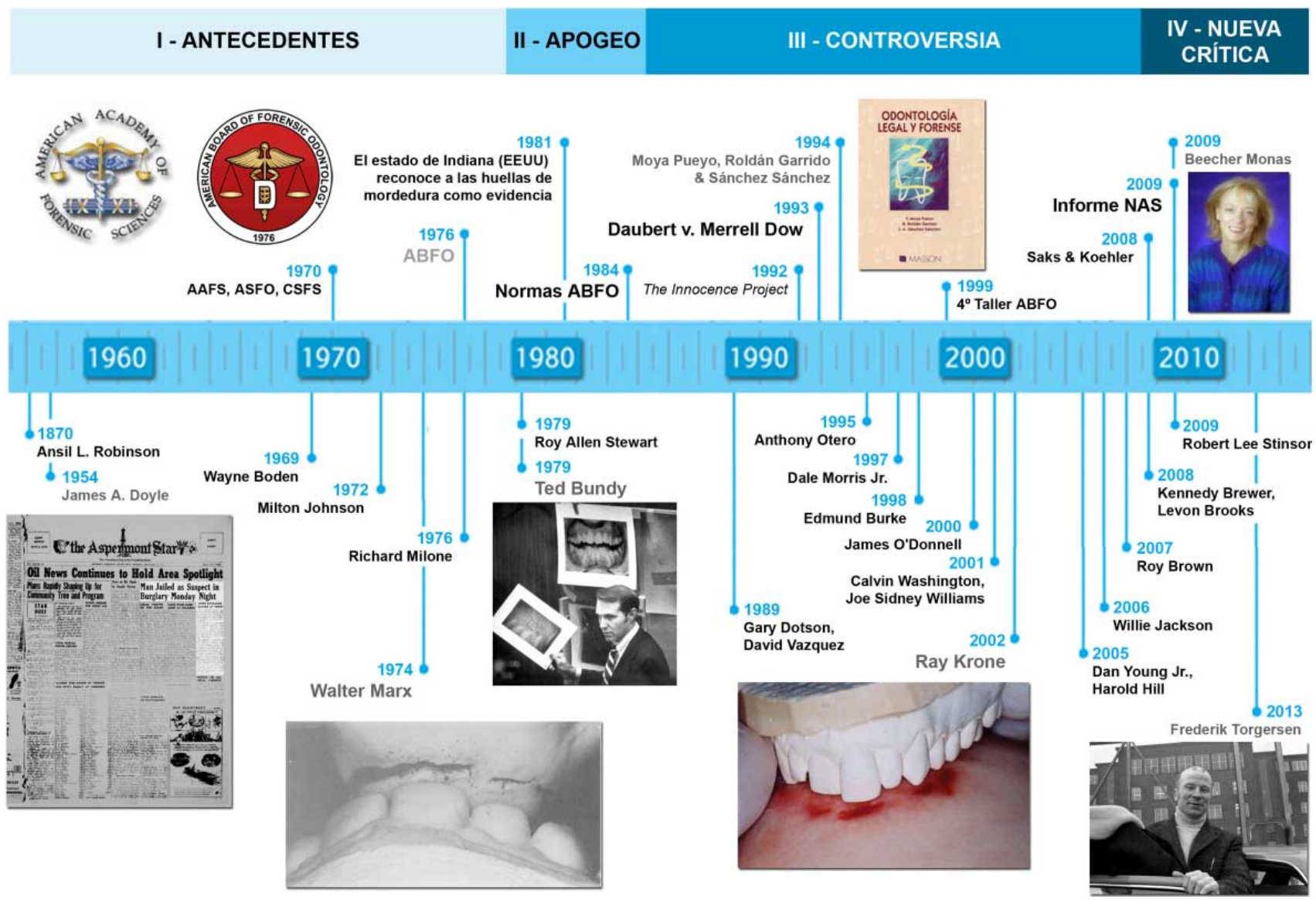

Figura 1. Esquema conceptual con distribución cronológica de casos, eventos y aportes de autor más relevantes y controversiales sobre los análisis de huellas de mordedura. Los años incluidos en el periodo "Controversia" son los correspondientes a las fechas de exoneración una vez comprobadas las condenas injustas. Imágenes arriba: izq., escudos de AAFS y ABFO; centro, aun cuando la obra de 1994 "Odontología Legal y Forense" de Moya Pueyo et al., continúa siendo un referente en habla hispana, su abordaje sobre los análisis de huellas de mordeduras se encuentra fuera del contexto cronológico sumamente controversial en el que se encuentra; izq., la abogada y magister Erica Beecher-Monas lidera una de las corrientes más discusivas y detractoras de este tipo de análisis. Imágenes abajo: izq. Nota señalando el robo donde sería atrapado James A. Doyle (The Aspermont Star, edición del 18 de diciembre de 1952); izq., centro: cotejo modelo dental de Walter Marx con reproducción de la huella en la nariz de su víctima, en 1974 (Vale et al. Unusual three-dimensional bite mark evidence in a homicide case. J Forensic Sci., 21(3):642-52, 1976); centro: el Dr. Richard Souviron presentando la evidencia en el juicio contra Ted Bundy en Florida (Florida Memory, Division of Library \& Information Services); der., centro: cotejo modelo dental de Ray Krone sobre la huella de la víctima Kim Ancona. Nótese la malposición del diente 21 (The Innocence Project); izq.: Frederik Fasting Torgersen en 1974, año de su liberación luego de cumplir 16 años de su condena por asesinato. Aun alegando su inocencia y apoyado en diferentes pericias, los tribunales de Noruega continúan negándole la revisión de su caso (Aftenposten, edición del 6 de diciembre de 2006. Fotografía de archivo). 
2009. Robert Lee Stinson (EE.UU.) es condenado en 1985 por poseer el mismo diente fracturado que dos odontólogos identificaron sin dudar en las huellas de mordedura de una mujer muerta a golpes. The Innocence Project tomó el caso en 2004 consolidando un equipo junto a Gregory Golden, presidente del Comité de control de protocolos ABFO y los odontólogos D. Senn, D. Murmann y N. Sperber. Los investigadores, de manera independiente, analizaron la evidencia y coincidieron que Stinson no podría haber dejado esas huellas. Las pruebas genéticas también le excluyeron con lo que finalmente fue exonerado y liberado en el año 2009 (Pretty \& Bowers; Lipton et al.; Deitch, 2009).

2013. Frederik Fasting Torgersen (Noruega), merece una especial atención. El odontólogo Ferdinand Strom realizó el análisis de una huella de mordedura en una muchacha violada y estrangulada. Su testimonio vinculó a Torgersen con lo que fue condenado y sentenciado en 1958. En 1976, y después de sucesivas apelaciones, el odontólogo sueco Gisele Bang nuevamente le identificó como el autor de la mordedura, confirmación que se repetiría en 1999 y 2000 por los peritos del Reino Unido, Gordon MacDonald y David Whittaker. En 2001, la defensa convocó a D. Senn para reexaminar la evidencia. Después de analizarla, se pusieron de manifiesto inconsistencias entre la huella y los dientes de Torgersen, conclusión en la que coincidieron Marden Alder, P. Stimson y C. Michael Bowers (quienes no conocían los antecedentes del caso). Así mismo, la defensa no ha logrado a la fecha un nuevo juicio para Torgersen (Senn \& Souviron).

\section{LA NUEVA CRÍTICA}

2008. Saks \& Koehler publicaron "The individualization fallacy in Forensic Science Evidence", donde postularon que el procedimiento de cotejo de informaciones (básico para una identificación fehaciente) puede verse afectado por malinterpretación o simple azar si una de las muestras está sesgada, si existe insuficiencia de estándares en la investigación o, lo que es peor, si existe subjetividad en el perito. Los autores recomendaron claridad y análisis lógico de probabilidades y una actitud honesta en los peritos, que no rellenen los vacíos probabilísticos con meras intuiciones o juicios pues "eso no es prueba científica" (Saks \& Koehler, 2008).

2009. El informe NAS. En abril de 2007, la National Academy of Sciences (NAS), dirigió una in- vestigación sobre las ciencias forenses identificadoras donde se incluyó al análisis de huellas demordeduras. El 18 de Febrero de 2009, la NAS publicó un informe de 254 páginas con el título "Strengthening Forensic Science in the United States: A Path Forward", donde expuso las necesidades científicas forenses y sus posibles soluciones (Committee on Identifying the Needs of the Forensic Science Community et al., 2009). Después de analizar el papel ejercido por los odontólogos forenses en los análisis de huellas de mordedura, el informe admitió que existe gran controversia respecto a su valor y confiabilidad. Este documento oficial ha sido uno de los disparadores del creciente escepticismo y descrédito de la técnica (Senn \& Souviron).

\section{DISCUSIÓN}

El año 2011, la Presidente de la ASFO, Mary Bush, afirmó: "¿Es el análisis de huellas de mordedura una pseudociencia, o simplemente un área forense sub-explorada que necesita de investigación sustancial para validar sus principios básicos? ¿Existen circunstancias en las que esta pericia deba ser utilizada aun cuando sus métodos no han sido probados?" (Bush, 2001). Leña al fuego. Bowers (2011) defendió esta posición, recriminando incluso la falta de respuestas de la AAFS y del ABFO al informe NAS. Barsley et al. (2012), todos miembros de esas dos asociaciones, desacreditaron a Bush y justificaron los estudios actuales aduciendo que la importancia de estos análisis no radica en la inviabilidad de la técnica, sino en la cualificación de los peritos que la utilizan. La respuesta de Bush no se hizo esperar; defendió lo realizado por su equipo, sus publicaciones y reafirmó que el cambio de paradigma debería afectar la validez jurídica tanto del perito como de la prueba: "Si el análisis de huellas de mordedura está fuera del campo de la investigación científica, entonces su validez no puede ser evaluada por métodos científicos. Si esta validez no puede ser probada, deberíamos preguntarnos: ¿es ciencia u opinión? ¿Puede así formar parte de un proceso judicial?" (Barsley et al.).

Este intercambio epistolar resume las peleas intestinas y las posiciones adoptadas por los protagonistas de la disciplina: fuertes investigadores unos, charlatanes otros, y un gran rango de grises en el medio. Cada uno de los casos presenta sus propias singularidades donde incluso peritos de importante reconocimiento y cualificaciones han debido retractarse por pericias erróneas. Desde la época en que el aná- 
lisis consistía en superponer modelos dentales sobre una huella o su fotografía, las cosas han cambiado gradual e irreversiblemente. El caso Marx fue un comienzo significativo pues estableció el gold standard procedimental y la inclusión de las huellas de mordedura como evidencia. Sucesivos fallos judiciales subrayaron así la admisibilidad de esta pericia (Pretty \& Sweet, 2006). Hoy la tendencia es bastante más escéptica. Deitch, explicita que la falta de demostración científica de la unicidad dental, la imposibilidad de analizar la piel como sustrato por su capacidad de distorsión, la escasa cantidad de dientes visibles en la huella, o incluso la predisposición y subjetividad del observador, colocan a los análisis de huellas de mordedura en una posición inferior y desprotegida como evidencia jurídica.

Beecher-Monas comparte esta perspectiva. Esta abogada, magister en Medicina y en Ciencias, y profesora de la Facultad de Derecho de la Wayne State University en Detroit (EE.UU.), publicó en 2009 "Reality bites: the illusion of science in bite-mark evidence", una ácida referencia a la problemática de las huellas de mordedura en los tribunales. Cuestionó el trabajo odontológico forense por su falta de estándares objetivos y controlables y por mantener sus pericias en un campo enteramente subjetivo. Según ella, si bien en los juicios civiles posteriores a la aparición de los Estándares Daubert los jueces no han tenido reparos en excluir a peritos "débiles", los casos penales no han sido tratados de igual manera. La mayoría de las veces, cuando un acusado ha cuestionado las bases científicas de las evidencias presentadas, los jueces han evadido su función de guardianes y no han dado lugar a esos cuestionamientos. Beecher-Monas aseveró que la identificación por huellas de mordedura falla en todos los puntos promovidos por Daubert.

Uno de los sucesos más discutidos lo constituyó el $4^{\circ}$ Taller de Huellas de Mordedura organizado por ABFO en 1999. Lo que se suponía iba a ser un ejercicio educativo de identificación, terminó en una de las más cuestionadas, nefastas y mediatizadas experiencias para la disciplina (Senn \& Souviron). El taller delató un margen excesivamente alto de error en las identificaciones de huellas de mordedura (63\%), resultados que Bowers revelaría para disgusto de muchos (Beecher-Monas). Senn \& Souviron calificaron a Bowers como "el más enigmático generador de desinformación" respecto de lo acontecido en ese taller, ya que habría tergiversado la información contradiciendo los resultados reales de una mera "instancia informal". Así mismo otros autores han reportado már- genes importantes de error en esta técnica, sin distinción significativa de entrenamiento o experiencia de los observadores (Pretty \& Sweet, 2001). Sería interesante recordar que este "error crítico" es análogo a "culpar a un inocente" (Avon et al., 2010).

Silver \& Souviron prefieren mantener una posición menos extrema. Aunque no posea la certeza de un análisis genético, una mordedura pueden evidenciar elementos morfológicos muy reveladores (sufrimiento, agresión o defensa, valoración lesional, perfil dental del agresor, antigüedad y reincidencia, relación espacial entre el agresor y el agredido). En una entrevista concedida a CNN, Levine defendió que el análisis de huellas de mordedura es vital e importante y está lejos de ser una pseudociencia, pero necesita aún mucha investigación (CNN, 2011). De lo que no hay dudas es que necesita de un odontólogo forense capacitado, cualificado y experimentado que conozca los alcances, pero sobre todo las limitaciones de la técnica.

Bowers (2006) Ilama la atención sobre lo "sorprendentemente escasa y carente de rigor científico" de la literatura en el tema, y agrega que "la comunidad odontológica forense se ha mantenido silenciosa", sobre las condenas injustas basadas en estas pericias. El mismo manual del ABFO, en su última revisión, recomienda escepticismo tanto de publicaciones como de presentaciones orales en congresos, examinar cuidadosamente su diseño metodológico, las referencias citadas, el tipo de análisis estadístico desarrollado o las conclusiones abordadas pues "...se ha demostrado que hasta las más respetables revistas arbitradas pueden publicar información inútil" (American Board of Forensic Odontology). La pregunta evidente: ¿dónde nos colocan a los hispanoparlantes estas afirmaciones y sugerencias?

Sobre el análisis de huellas de mordedura, resulta interesante la evaluación publicada por De los Ríos \& Barriga sobre la presencia de los estándares ABFO en la literatura de habla hispana. Detectaron 72 publicaciones entre los años 1987 y 2011 donde: a) existe un aumento de referencias a partir de "Odontología Legal y Forense" de Moya Pueyo et al. (1994), obra que catalizó la investigación en el idioma español, pero en un análisis actual, "...con un escaso soporte técnico para el profesional que debe someterse al escrutinio procedimental en juicio"; b) un importante dominio de las publicaciones médicas $(56,9 \%)$ por sobre las odontológicas $(27,8 \%)$, evidente dada la naturaleza médico-legal de las mordeduras, pero peligrosa si se toma en cuenta que se ha recomendado 
que esta pericia sea realizada por un odontólogo forense. No es un dato menor destacar que solo un $34,7 \%$ de esas referencias estuvo conformado por artículos publicados en revistas arbitradas (25/72) y que ninguno de ellos representó la mayor presencia de los estándares ABFO. Los autores concluyeron que "...existe una escasa presencia de los estándares ABFO en la literatura de habla hispana", preguntándose si existe una falta de interés en el hispanohablante hacia la literatura en idioma inglés. Consideran que la reticencia a este idioma puede deberse a la suposición de que las circunstancias sociales, geográficas y culturales no serían aplicables a las hispanas. Según diferentes y reconocidos autores, este razonamiento es ingenuo, pues cualquier conflicto judicial puede ser extrapolable dado que todos los sistemas jurídicos y periciales pueden exhibir las mismas debilidades (Pretty \& Bowers; Pretty \& Sweet, 2010), tal y como lo certifican los casos presentados en esta revisión. The Innocence Project ha impulsado su movimiento en no menos de siete países, y ha expandido sus fronteras bajo el nombre de The Innocence Network (www.innocencenetwork.org). Bernitz (2009) ha sido explícito al referir que "necesitamos cooperar con nuestros colegas alrededor del mundo esforzándonos para obtener los niveles más altos en nuestros estándares y calidad". Por desgracia, la literatura de habla hispana escasamente aporta investigación o reportes de sus casos (Reilly, 2012; Güerri Ripol \& Lucena Romero, 1995).
Según Senn \& Souviron, los casos controvertidos son una excelente oportunidad de aprendizaje y de revisión permanente de cada uno de los factores que los afectaron en su desarrollo. Más importante aún, se puede comparar a los encarcelamientos injustos con un accidente aéreo, donde rara vez son el producto de un único fallo, pero una pericia sesgada o aberrante no puede dejar de ser considerada, fundamentalmente, por el papel jugado por el experto, por su experticia, por la introducción de ésta en el proceso penal o por el control y guarda del juez y de la contraparte (Pretty \& Bowers). Coincidimos en que el futuro de los análisis de huellas de mordeduras dependerá de que los odontólogos forenses conserven marcos éticos impecables combinados con el uso de protocolos internacionales, procedimientos y opiniones permanentemente actualizados y firmemente enraizados en ciencia. Ellos deben comprometerse al estudio continuo, la experimentación y el aprendizaje, y de ser convocados, tener la visión, la energía, el coraje y la humildad para hacer los cambios que sean necesarios (Senn \& Souviron).

AGRADECIMIENTOS. Agradecemos el apoyo de la Comisión Nacional de Investigación Científica y Tecnológica de Chile (CONICYT) a través de su Programa de Inserción y Atracción de Capital Humano Avanzado MEC, Proyecto Folio 80120014 - CONICYT, Chile.

FONSECA, G. M.; BRIEM-STAMM, A. D.; CANTÍN, M.; LUCENA, J. \& BENTKOVSKI, A. Forensic Dentistry I: Bite Marks. Int. J. Odontostomat., 7(1):149-157, 2013.

ABSTRACT: Among the forensic dental identification, the analyses of bite marks have represented a current, relevant and controversial topic. The uniqueness of the dentition, the accuracy of bite marks on skin and the analytical techniques have been severely questioned because of the relevant casuistry of wrongful convictions. While the specialized and more current literature offers a permanent review on protocols and standards for verifying expertise, the Spanish literature does not keep pace with this situation, with scanty updating of procedures, primary investigation or case reports. Since these analyses have been modified in their bases, a proper update of Spanish literature to allow the adjustment of their axioms is needed. We present a chronological review of cases and inferential issues in bite mark analysis as judicial evidence, and the new epistemological postulates for the forensic significance of this type of evidence are discussed.

KEY WORDS: forensic dentistry, bite mark, bite mark analysis, wrongful convictions.

\section{REFERENCIAS BIBLIOGRÁFICAS}

American Board of Forensic Odontology. ABFO Reference Manual. Revisión del 22 de Enero, 2013. Disponible en: http:// www.abfo.org/

Avon, S. L.; Victor, C.; Mayhall, J. T. \& Wood, R. E. Error rates in bite mark analysis in an in vivo animal model. Forensic Sci. Int., 201(1-3):45-55, 2010.

Barsley, R.; Freeman, A.; Metcalf, R.; Senn, D. \& Wright, F. Bitemark analysis. J. Am. Dent. Assoc., 143(5):444, 446; author reply 446, 448, 2012. 
Beecher-Monas, E. Reality bites: the illusion of science in bitemark evidence. Cardozo Law Review, 30(4):1369-410, 2009.

Bernitz, $\mathrm{H}$. The challenges and effects of globalisation on forensic dentistry. Int. Dent. J., 59(4):222-4, 2009.

Bowers, C. M. Problem-based analysis of bitemark misidentifications: the role of DNA. Forensic Sci Int., 159 (Supp/ 1):S104-9, 2006.

Bowers, C. M. Bitemark analysis. J. Am. Dent. Assoc., 142(12):1334-5, 2011.

Bush, M. A. Forensic dentistry and bitemark analysis: sound science or junk science? J. Am. Dent. Assoc., 142(9):997-9, 2011

Clement, J. G. \& Blackwell, S. A. Is current bite mark analysis a misnomer? Forensic Sci. Int., 201(1-3):33-7, 2010.

CNN. Anderson Cooper $360^{\circ}$. Video: Bite marks led to wrongful conviction. 21 de Diciembre, 2011. Disponible en: http:// ac360.blogs.cnn.com/2011/12/21/video-bite-marks-led-towrongful-conviction/

Collins, J. M. \& Jarvis, J. The wrongful conviction of forensic science. Forensic Sci. Pol. Manag., 1(1):17-31, 2009.

Committee on Identifying the Needs of the Forensic Science Community; Committee on Science, Technology \& Law Policy and Global Affairs, Committee on Applied and Theoretical Statistics, Division on Engineering and Physical Sciences. National Research Council of the National Academies. Strengthening Forensic Science in the United States: A Path Forward. Washington DC, The National Academies Press, 2009.

De los Ríos, E. \& Barriga, M. Análisis de Huellas de Mordeduras: Presencia de Estándares ABFO en la Literatura en Idioma Español. FOPJ, 2 (4):25-32, 2011.

Deitch, A. An inconvenient tooth: Forensic Odontology is an inadmissible junk science when it is used to "match" teeth to bitemarks in skin. Wis. Law Rev., 5:1205-36, 2009.

Fisher, J. Forensics under fire. Are bad science and dueling experts corrupting criminal justice? New Brunswick, Ed. Rutgers University Press, 2008.

Güerri Ripol, F. J. \& Lucena Romero, J. Identificación del autor de una agresión sexual por las marcas de mordedura dejadas en la víctima. Terceres Jornades Catalanes D’Actualització en Medicina Forense. Cataluña, Departamento de Justícia, Generalitat de Catalunya, 1995. pp. 237-39.

Kennedy, D. Forensic Dentistry and Microbial Analysis of Bite Marks. APJ, 6-15, 2011.

Lipton, B. E.; Murmann, D. C. \& Pavlik, E. J. History of Forensic Odontology. En Senn, D. R. \& Weems, R. A. (Eds.). ASFO. Manual of Forensic Odontology. $5^{\text {th }}$ ed. Boca Raton, CRC Press, 2013.
Moya Pueyo, V.; Roldán Garrido, B. \& Sánchez Sánchez, J. A. Odontología legal y forense. Barcelona, Masson, 1994.

Page, M.; Taylor, J. \& Blenkin, M. Expert Interpretation of Bitemark Injuries-A Contemporary Qualitative Study. J. Forensic Sci., 58(3):664-72, 2013.

Pierce, L. J.; Strickland, D. J. \& Smith, E. S. The case of Ohio v. Robinson. An 1870 bite mark case. Am. J. Forensic Med. Pathol., 11(2):171-7, 1990.

Pretty, I. A. \& Bowers, C. M. Wrongful Convictions and Erroneus Bitemark Opinions. En Dorion, R. B. J. (Ed.). Bitemark Evidence. A Color Atlas and Text. $2^{\text {nd }}$ ed. Boca Raton, CRC Press, 2011.

Pretty, I. A. \& Sweet, D. J. Digital bite mark overlays--an analysis of effectiveness. J. Forensic Sci., 46(6):1385-91, 2001.

Pretty, I. A. \& Sweet, D. J. The judicial view of bitemarks within the United States Criminal Justice System. J. Forensic Odontostomatol., 24(1):1-11, 2006.

Pretty, I. A. \& Sweet, D. J. A paradigm shift in the analysis of bitemarks. Forensic Sci. Int., 201(1-3):38-44, 2010.

Reilly, M. Evidencia de mordeduras en un caso controversial. FOPJ, 3 (6):18-21, 2012.

Saks, M. J. \& Koehler, J. J. The individualization fallacy in Forensic Science Evidence. Vand. Law Rev., 61:1:199-219, 2008.

Senn, D. R. History of Bitemark Evidence. En: Dorion, R. B. J. (Ed.). Bitemark Evidence. A Color Atlas and Text. $2^{\text {nd }}$ ed. Boca Raton, CRC Press, 2011.

Senn, D. R. \& Souviron, R. R. Bitemarks. En: Senn, D. R. \& Stimson, P. G (Eds.). Forensic Dentistry. $2^{\text {nd }}$ ed. Boca Raton, CRC Press, 2010.

Silver, W. E. \& Souviron, R. R. Dental autopsy. Boca Raton, CRC Press, 2009.

Dirección para Correspondencia:

Gabriel M. Fonseca, D.D.S., Ph.D

Mariano Moreno 937, Cordoba

Zip code: X5000MRS.

ARGENTINA

Email: gabriel_fonseca@argentina.com

Recibido : 12-12-2012

Aceptado: 09-01-2013 